\title{
ENSAIO DE IMPERMEABILIZAÇÃO COM ADITIVOS EM SITUAÇÕES SUJEITAS A INFILTRAÇÕES
}

\author{
DENARDI, ISABELA BARBOSA \\ Engenheira \\ PUCRS \\ Rio Grande do Sul; Brasil \\ e-mail: isabela.denardi@acad.pucrs.br
}

\author{
ROHDEN, ABRAHÃO BERNARDO \\ Professor \\ FURB e PUCRS \\ Rio Grande do Sul; Brasil \\ e-mail: abrahao.rohden@pucrs.br
}

\begin{abstract}
RESUMO
A adição de aditivos hidrofugantes em argamassas tem como função tornar o ambiente mais salubre ao usuário, minimizando problemas de infiltrações indesejadas. Desta forma, este artigo apresenta a influência de adição de aditivos hidrófugos a misturas de argamassas. Foram realizados três tipos de amostras de argamassa, uma sem aditivos e outras duas com aditivos distintos. Foram moldadas amostras de 30x30x3 cm de argamassa com aplicação em duas camadas conforme previsto em norma. Após a cura adequada, foi realizada a aplica uma coluna d'agua sobre as amostras e deixado em repouso por 24 horas. Os resultados obtidos mostraram que com a adição de aditivos hidrófugos na mistura da argamassa houve uma boa melhoria no desempenho de permeabilidade de todas as seis amostras ensaiadas com adição de impermeabilizantes, quando comparadas a amostras sem adição de aditivos.
\end{abstract}

Palavras-chave: aditivo hidrofugante, estanqueidade, manifestações patológicas.

\section{ABSTRACT}

The addition of waterproofing additives in mortars has the function of making the environment healthier for the user, minimizing problems of unwanted infiltration. Thus, this paper presents the influence of adding water repellent additives to mortar mixtures. Three types of mortar samples were made, one without additives and two with different additives. 30x30x3 cm samples of mortar were molded with application in two layers as provided for in the standard. After proper curing, a column of water was applied to the samples and allowed to stand for 24 hours. The results showed that with the addition of waterproof additives in the mortar mix there was a good improvement in the permeability performance of all six samples tested with the addition of waterproofing when compared to samples without additives.

Keywords: water repellent additive, watertightness, pathological manifestations.

\section{INTRODUÇÃO}

No cenário da construção civil são realizadas obras para diversas funções, sejam elas residenciais, comerciais ou industriais, utilizado em diversos métodos de construção. Estas estruturas quando submetidas aos efeitos da água, com o passar do tempo, podem apresentar manifestações patológicas em vários pontos. Tais manifestações são causadoras de problemas estruturais, de insalubridade e de umidade na edificação (CRUZ, 2003).

Ao longo do tempo a técnica de impermeabilização foi sendo aprimorada. Estudos apontam que a impermeabilização começou a ser utilizada em barcos de madeira e até mesmo na estrutura dos Jardim Babilônicos. Neste período, alguns dos produtos que eram utilizados materiais impermeabilizantes, eram óleo de baleia e petróleo, para suprir tal demanda, a fim de sanar as manifestações patológicas existentes (IBI, 2017).

No Brasil, o assunto foi debatido quando iniciaram as obras de construção do metrô de São Paulo, em 1968, onde técnicos verificaram a importância de sua regulamentação (IBI, 2017). Em 1975, ambas das normas de impermeabilizações foram implementadas, a NBR 9575 (ABNT, 2010) e da NBR 9574 (ABNT, 2008) sobre execução de impermeabilizações, informam as exigências, detalhes construtivos e recomendações a serem seguidas quando da realização de uma edificação. 
Junto às normas de impermeabilição foi instituído o IBI (Instituto Brasileiro de Impermeabilizações), que tem por finalidade principal o estudo, a pesquisa, o desenvolvimento de produtos, serviços e do mercado de produtos químicos voltados para a construção, conforme descrição feita pela própria instituição.

Devido ao custo de implantação ou da desinformação sobre o uso de certos produtos, a manutenção necessária e os cuidados exigidos para que a proteção da estrutura não seja colocada em risco, a impermeabilização por vezes é deixada de lado na construção civil. Segundo estudos realizados pelo Instituto Brasileiro de Impermeabilização no ano de 2017 , o custo da implantação deste serviço equivale a $2 \%$ do custo total da obra, algo relativamente pequeno, tendo em vista o posteriormente custo gerado ao usuário. No entanto, caso a estrutura não receba a adequada impermeabilização, o reparo que deverá sem implementado acarretará em $10 \%$ do custo total da obra, sem contabilizar todo o transtorno causado ao usuário da edificação.

São diversas as técnicas e tipos de aplicação de impermeabilizações conhecidas, além das muitas que ainda se encontram em pesquisas. É importante que o profissional responsável tanto pelo projeto como pela execução esteja bem informado sobre os tipos e aplicações específicas de cada tipo de material. Muitas vezes são utilizados nas edificações revestimentos sem a aplicação de impermeabilizantes, porque aos olhos do consumidor é algo desprezível. No entanto, com o passar do tempo, pois são notórias as manifestações patológicas na edificação. A água, em todos os seus estados físicos, é um dos maiores causadores de manifestações patológicas. Estudos apontam que a maioria dos sinistros e problemas causados em construções são gerados devido a infiltrações de água (PINTO, 1996).

O objetivo deste trabalho foi realizar um comparativo de desempenho de dois aditivos hidrofugantes comumente empregado na impermeabilização de vigas baldrame. Realizar três amostras de argamassa com e sem adição de impermeabilizantes e analisar a mudança de permeabilidade de cada uma delas. O trabalho se delimitou ao estudo de argamassas aditivadas com aditivo hidrófugo, principalmente para aplicação em vigas de baldrame. Realizadas somente análises de permeabilidade, sem levar em conta demais características que podem ser desenvolvidas pela adição deste aditivo.

\section{SISTEMA DE IMPERMEABILIZAÇÃO}

Com a implantação da NBR 15575 (ABNT, 2013), norma de desempenho de edificações habitacionais, marcou-se uma evolução no ramo da construção civil na padronização, nos regimentos e na qualidade das obras a serem executadas. A referida norma traz parâmetros e relações qualitativas que devem ser alcançadas no momento em que se constrói uma edificação. Cada vez mais, construtores, projetistas e fornecedores buscam aprimorar materiais e técnicas construtivas a fim de um objetivo comum: a qualidade da construção.

A norma e o Código de Defesa do Consumidos, em conjunto tratam de questões de garantia aos serviços prestados aos clientes, as edificações habitacionais que devem atender um nível de desempenho mínimo para sua vida útil. Este é determinado pelo projeto conforme exigência da norma brasileira. Garantindo que os elementos que compõem um imóvel residencial devem ter durabilidade e condições adequadas conforme especificações, projetos e execução (IBI, 2017).

A NBR 15575 (ABNT, 2013) traz parâmetros e exigências que devem ser seguidas durante a execução de uma edificação na construção civil. Ela fornece ao profissional os critérios esperados para que sejam realizados trabalhos seguros e adequados. A impermeabilização é citada na NBR 15575 (ABNT, 2013) na parte inicial, em requisitos gerais. Alertando que a edificação deve ter estanqueidade frente a umidades, tanto na sua cobertura para a água da chuva, quanto em solos e lençóis freáticos, evitando a aparição de umidade, e impermeabilização de áreas úmidas internas da edificação. Retrata as questões de cobertura das habitações, aponta critérios para aceitação de execução de coberturas impermeabilizadas com teste de estanqueidade que devem durar no mínimo 72 horas.

A impermeabilização dispõe normas específicas, uma delas é NBR 9575 (2010), traz recomendações e exigências para elaboração de projetos de impermeabilização, a fim de atingir os requisitos mínimos de proteção da edificação. Requisitos estes como a passagem de fluidos, tornando o ambiente salubre, seguro e confortável ao usuário, e garantindo a estanqueidade dos elementos que a requerem. São tratadas as técnicas para realização das impermeabilizações, os tipos de impermeabilização e recomendações para preparação de substrato. Aborda a maneira como o produto deve ser preparado para a aplicação, recomendações para busca de informações junto aos fornecedores de produtos, visto que cada produto tem um desempenho frente as situações determinadas. Aborda recomendações de aplicações genéricas para cada tipo de técnica e a proteção que deve ser realizada após a aplicação do produto. Aborda detalhadamente cada tipo de impermeabilização, sua dosagem, resistência do material, para qual situação é mais usual e em que tipo de superfície é 
aplicável. Trata tanto de impermeabilizações rígidas como de flexíveis. Ao final descreve alguns exemplos sobre aplicações e detalhes de projeto, os quais devem ser seguidos na execução para um bom resultado final e para não comprometer a proteção da superfície. É importante que se tenha um estudo apropriado para cada situação, visando o melhor aproveitamento de cada tipo de material para a situação exigida.

Junto à norma citada anteriormente, pode-se citar a NBR 9574 (ABNT, 2008) que trata sobre a execução de impermeabilizações, ambas devem ser estudadas em conjunto. É aplicável às obras de edificações em geral, que já estão em fase de execução ou que ainda podem sofrer acréscimo de execução ou reforma para sanar problemas vigentes.

Visto que os maiores causadores de patologias encontrados na construção civil são relacionados a problemas ligados a umidade e infiltrações nas edificações importância do estudo e a aplicação adequada dos métodos são importantes para que não sejam realizados retrabalhos futuros de manutenção (PINTO, 1996). A umidade, além de ser um causador de patologia em edificações, pode trazer malefícios à saúde do morador, como causar problemas respiratório, desconforto ao usuário e insalubridade da edificação (BARBOSA, 2018).

Cunha e Neumann (1979) identificam alguns locais que devem receber impermeabilizações, como telhados, coberturas planas, terraços, áreas descobertas, calhas de escoamento de águas pluviais, caixa d'agua, piscina, tubulações hidráulicas. Mas também em locais de pisos molhados, paredes que recebem água da chuva, esquadrias, peitoris, soleiras de portas externas e demais águas que podem subir por capilaridade.

As impermeabilizações são classificadas conforme a sua capacidade de flexibilidade perante ao comportamento físico da estrutura, podendo ser materiais de características flexíveis ou rígidas. Impermeabilizações do tipo rígidas não suportam condições de flexibilidade compatíveis e aplicáveis à edificação, assim como não suportam movimentações da mesma NBR 9575(ABNT, 2010). A aplicação deve ser realizada em áreas onde não haja flexão da edificação, ou seja, em locais onde é menos propícia a aparição de trincas e fissuras, o que pode comprometer este tipo de impermeabilização. Esta impermeabilização é mais utilizada para fundações, pisos internos de contato com o solo, contenções de solo e piscinas em situações enterradas (FERREIRA, 2012). Argamassas com adição de aditivos, modificadas com polímeros, poliméricas, cimento cristalizantes e membranas epóxicas são alguns tipos de impermeabilizações classificadas como rígidas.

Impermeabilizações do tipo flexível são produtos de características flexíveis, aplicáveis em locais que apresentem movimento do elemento construtivo, porém, "para ser caracterizada como flexível, a camada impermeável deve ser submetida a ensaio" NBR 9575 (ABNT, 2010). Devem ser compostas por mantas ou por elastômero dissolvido, seja em modo de pintura ou aplicação em várias camadas. Podem ser citadas as emulsões asfálticas e acrílicas como também outras com termoplásticos e elastômeros dissolvidos (CUNHA E NEUMANN, 1979).

\subsection{Argamassa impermeável com aditivo hidrófugo}

A argamassa é uma mistura composta de cimento, areia e água, utilizada para revestimentos, assentamento de tijolos, vigas de baldrame e demais atividades em construção civil. A norma com maiores especificações técnicas das argamassas é descrita na NBR 13281 (ABNT, 2005). Geralmente são adicionados à mistura aditivos impermeabilizantes para que tenha uma melhora em alguns fatores.

A argamassa com aditivo hidrófugo possui características de impermeabilização rígida. Tem como finalidade a melhora do desempenho do material nos quesitos relacionados a retenção de fluidos e trabalhabilidade, permitindo uma redução da relação água/cimento NBR 9574 (ABNT, 2008). Para estas misturas, normalmente os produtos são adicionados em pequenas quantidades (não maior que $5 \%$ do peso total de cimento usado no traço).

É necessário um estudo apropriado para cada situação na qual será aplicada a argamassa, pois para cada situação haverá recomendação de dosagem específica, bem como se faz necessário o controle do traço da massa utilizada. A correta aplicação do material é imprescindível, já que a massa apresentará uma característica com menor trabalhabilidade e também a menor homogeneização da mistura (CUNHA E NEUMANN, 1979).

Os aditivos hidrófugos são um dos tipos de impermeabilizações mais utilizados no mercado. Presentes na forma líquida ou em pó, são compostos de estearatos e silicatos, na presença de cloretos, dando origem ao aditivo NBR 9574 (ABNT, 2008). Tais compostos são adicionados a mistura em pequenas quantidades que, ao entrarem em contato com os capilares da massa, têm o objetivo de selar e fechar os poros e orifícios da argamassa. 
A VEDACIT (2017), um dos maiores fornecedores de aditivos hidrofulgantes do Brasil, informa que "os aditivos impermeabilizantes atuam de forma direta nos poros de argamassas e concretos, formando uma fina película que absorve a água e ajuda a tamponar esse poro". Tais aditivos são indicados para aplicação em vigas de baldrame, assentamentos de alvenaria, aplicação de revestimentos em pisos e paredes, muros de arrimo, estruturas enterradas (reservatórios, piscinas, subsolos e caixas d'agua) e concreto impermeável. (VEDACIT, 2017).

A mistura dos componentes da argamassa deve ocorrer no local da obra, não devendo ser de origem industrial devido ao rigoroso controle e dosagem dos materiais que serão utilizados para o preparo. O preparo da argamassa com adição de impermeabilizantes de aditivo hidrófugo se dá pela utilização de água potável, cimento Portland, areia de classificação média (lavada, peneirada conforme granulometria de $0,075 \mathrm{~mm}$ a $3 \mathrm{~mm}$ e sem materiais e substâncias argilosas) e aditivo hidrófugo NBR 9574 (ABNT, 2008). As recomendações referentes ao traço e tipo de cimento a serem utilizados são informadas pelo fabricante na embalagem do aditivo em uso, de acordo com as melhores aplicações previamente testadas por ele.

Conforme recomendações da NBR 9574 (ABNT, 2008), para a aplicação da argamassa é necessário que a estrutura já tenha recebido uma camada de chapisco de cimento e areia, a qual tem a finalidade de aderir a massa ao substrato bruto e umedecido. Deve ser realizada com espessura máxima de $30 \mathrm{~mm}$ com aplicações em duas camadas de $15 \mathrm{~mm}$, sendo esta primeira sarrafeada, a fim de ancorar a camada seguinte, a mesma deverá será manualmente adensada para minimizar o índice de vazios. Na mesma Norma, é citado que as camadas devem ser realizadas no mesmo dia. Caso contrário, é necessária a realização de chapisco para ancoramento da última camada. Aconselha-se cura de no mínimo 3 dias para este tipo de técnica e que seja realizada a proteção mecânica em locais onde é possível que aconteça agressão mecânica.

Para a aplicação da argamassa com aditivo hidrofugante, é importante salientar alguns requisitos previstos em norma para que a aplicação seja realizada da maneira correta. É pedido que se tenham declives de superfície de no mínimo de $1 \%$, uma preparação adequada do substrato com a devida limpeza, secagem, correção de possíveis ninhos e falhas de concretagem, assim como a retirada de todos os corpos estranhos da superfície. O substrato deve estar seco e com um intervalo de cura de 7 dias do dia da concretagem, deve-se também fazer os devidos preparos em canos e estruturas passantes, conforme previsto na Norma. Após a aplicação, a argamassa apresenta características de baixa permeabilidade e com uma durabilidade maior, quando comparada à uma argamassa convencional. No mercado da construção civil é possível encontrar diversas marcas e tipos de aditivos hidrófugos. É recomendável que seja consultado o manual de aplicação antes da realização dos serviços em obra.

\subsection{Manifestações Patológicas}

A palavra patologia é de origem grega, páthos = doença e logos = estudo, o que podemos entender como um estudo de doenças relacionada à área das ciências (NAZARIO E ZANCAN, 2010). Dentro do cenário da impermeabilização, podemos citar diversos tipos de manifestações patológicas na edificação devido à falha de projetos ou de execução inadequada dos profissionais da área.

Há muitos anos são constatadas manifestações patológicas no que diz respeito a impermeabilizações na construção civil, podendo aparecer de diversas formas: umidades, trincas e fissuras, bolhas em pinturas e descolamento de revestimentos. Ao se analisar uma edificação, é rara a não constatação de algum tipo de patologia (NAZARIO E ZANCAN, 2010).

Ripper (1984), descreve a manifestação patológica como uma redução ou término do desempenho da estrutura, sobre estabilidade, estética e durabilidade, que está relacionada diretamente às condições nas quais a estrutura é submetida. Os estudos destas manifestações servem para que possam ser identificados os problemas elencados e para que seja realizado um estudo apropriado para correção das patologias. Ela não serve somente para que os problemas sejam reparados e adequados, mas sim, para que se tenha um histórico de comportamentos das edificações, a fim de ser um meio de consulta para profissionais da área.

Como citado anteriormente, as manifestações patológicas mais incidentes na construção civil são relacionadas a impermeabilização, tornando o estudo de suma importância. Devido à necessidade de tratar o assunto da maneira adequada, cada vez mais são abordados assuntos de patologia de impermeabilizações, em artigos, publicações e conferências sobre o assunto (PINTO, 1996).

Uma pesquisa realizada por Pinto (1996) elenca as principais manifestações patológicas de impermeabilizações e distribuindo-as em porcentagens perante aos casos. Esta mostra com maior incidência os casos de: manchas de umidade, 
corrosão de armaduras, gotejamento de água e eflorescências. Ainda em seu estudo, aponta as condições e prováveis causas de falhas para que tenham acontecido certas manifestações, traz como principal causa os erros de concepção, efeito das variações dimensionais, erros de cálculo, erro de execução, entre outros.

Conforme citado por Souza (2008), a umidade traz desconforto ao usuário e rapidamente pode atingir a estrutura da edificação, o que pode causar um custo maior de implantação de reparos do substrato e da estrutura. Sendo uma das maiores causadoras de manifestações patológicas, causando manchas na superfície como paredes, pisos, fachadas, concreto armado, e normalmente não estão ligados à um único causador do problema.

A corrosão da armadura pode ocorrer em uma seção específica ou em toda a estrutura, devido à natureza eletroquímica das armaduras, em presença de água, causa a formação de óxidos e hidróxidos de ferro (PINTO, 1996). Ainda sobre a umidade, a mesma pode ser um causador de queda de gesso, gotejamentos, nascimento de vegetação na estrutura, eflorescências e vesículas (PINTO, 1996).

\subsection{Trabalhos recentes sobre o tema}

Bif e Pelisser (2013), realizaram testes com diversas argamassas para assentamento de revestimento externo. Pelos testes realizados, concluíram que as argamassas aditivadas apresentaram um desempenho maior que o mínimo aceitável. Foram realizados testes de argamassa com cal hidratada, os quais apresentaram melhores resultados da pesquisa, como ensaio de permeabilidade sendo $246 \%$ menos permeável que argamassas aditivadas e módulo de elasticidade próximo de 5 GPa. No entanto, apresentou problemas de fissuração no primeiro dia, o que pode comprometer a qualidade de vedação dos revestimentos externos.

A partir das pesquisas realizadas ainda por Bif e Pelisser (2013), o custo de um aditivo hidrófugo chega a ser três vezes maior que o custo de um aditivo incorporador de ar, sendo que ambos apresentam resultados próximos. De forma geral, foi concluído que a melhor argamassa estudada foi a com acréscimo de cal hidratada. Sobre as argamassas com aditivo hidrofugante citam que obtiveram os piores resultados. Provam que hidrófugos quando adicionados à argamassa não trazem diferença no resultado quando aplicados em revestimento.

Wiedmann (2006), realizou um estudo prático do uso de aditivos hidrofulgantes em blocos de concreto. Os testes apontaram que os blocos feitos com aditivos hidrofugantes em sua composição apresentam pouca permeabilidade, porém comprometem parte de sua resistência. Constatou também que a produção em escala fabril não afeta seu comportamento, mas deve ter um controle de qualidade na mistura dos elementos para que ocorra a devida homogeneização. Ademais, concluiu que uma parede com maior espessura tende a minimizar a consequência de pequenas falhas no interior dos blocos. Deve-se sempre ter controle da superfície dos blocos. Para que seja realizada a aplicação de blocos em alvenaria estrutural aparente, o autor aconselha que sejam realizados novos estudos sobre a relação bloco-argamassa a fim de obter amostras e melhores resultados sobre a baixa permeabilidade.

\section{MATERIAIS E MÉTODOS}

\subsection{Materiais utilizados}

Para a realização do estudo, foram utilizados produtos conforme indicações NBR 9574 (ABNT, 2008), e como se trata de uma argamassa com adição de aditivo, foram utilizados: cimento, areia, água e aditivos. A norma especifica que o traço de cimento e areia é de 1:3 (1 kg de cimento para $3 \mathrm{~kg}$ de areia), $2 \mathrm{~L}$ de aditivo para cada $50 \mathrm{~kg}$ de cimento e relação água/cimento de 0,62 .

\subsubsection{Cimento}

O cimento utilizado foi o Cimento Pozolânico CPIV-32, o qual apresenta característica de maior impermeabilidade e durabilidade comparado aos demais tipos de cimento. Esta característica se dá, pois, o cimento apresenta maior calor de hidratação, resistência a ataque de sulfatos e cloretos e uma maior resistência à compressão em idades avançadas. Indicado para aplicação em argamassas de assentamento e revestimento, estruturas de concreto, pisos, artefatos de concreto, obras subterrâneas, galerias e obras próximas ao mar (INTERCEMENT, 2018). A massa específica média do CP IV-32 utilizado é $2,83 \mathrm{~g} / \mathrm{cm}^{3}$ (ITAMBÉ, 2018). 


\subsubsection{Cimento}

A areia foi utilizada conforme indicação da norma, peneirada média. A areia utilizada foi ensaiada no Laboratório de Materiais da Pontifícia Católica do Rio Grande do Sul para a massa específica e a curva granulométrica. A massa unitária da areia ensaiada é de $1,49 \mathrm{~g} / \mathrm{cm}^{3}$.

\subsubsection{Aditivo}

Foram escolhidos dois tipos de aditivos para elaboração do estudo. O primeiro utilizado, denominado Aditivo 1, sendo este um aditivo hidrófugo recomendado pelo fabricante para impermeabilização de concretos e argamassas. Através da hidrofugação de partículas capilares, permite a selagem dos materiais e mantém os ambientes onde são aplicados argamassas ou concreto com o aditivo, salubres (VEDACIT, 2017). Conforme indicações da NBR 9574 (ABNT, 2008) e do fornecedor do produto, deve ser realizada a dosagem de 2 litros de aditivo para cada saco de $50 \mathrm{~kg}$ de cimento utilizados na mistura. Com densidade de $1,05 \mathrm{~g} / \mathrm{cm}^{3}$, composta basicamente por silicatos e de aparência de emulsão pastosa branca.

O segundo aditivo escolhido para utilização no estudo, denominado Aditivo 2, é um aditivo com função também impermeabilizante. As ações do aditivo vão além da impermeabilização, e agem na colagem e na redução da retração da argamassa. Com indicação de aplicação como do aditivo anterior, e com característica de aparência também em emulsão porosa branca.

\subsection{Métodos}

Para que sejam realizados os testes em argamassas, neste trabalho foi seguida a seguinte ordem para execução dos ensaios, as quais serão detalhados durante o decorrer do trabalho. As etapas principais da execução podem ser analisadas na Figura 1 .

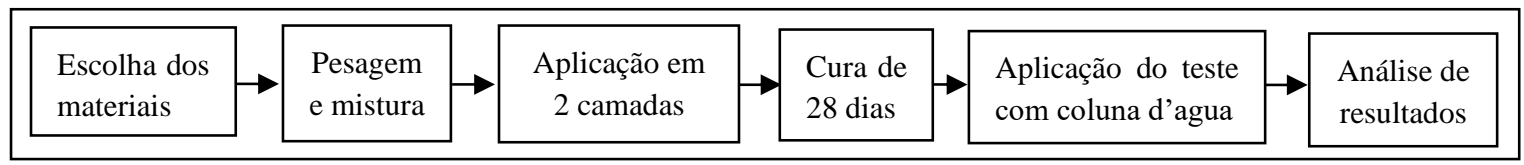

Figura 1: Fluxograma com as principais atividades do trabalho.

Como não existe normatização para teste de estanqueidade de argamassas, foi adotado o parâmetro de normativa do teste de permeabilidade em telhas de cimento da NBR 14858 (ABNT, 1997). Para a realização do estudo, toda a parte prática do projeto foi executada no Laboratório de Materiais de Construção da Pontifícia Universidade Católica do Rio Grande do Sul.

Com o intuito de analisar a eficácia de dois aditivos impermeabilizantes tipicamente utilizados na construção civil, foram realizadas três misturas e colocadas em análise de permeabilidade. Para maior precisão dos resultados, foram feitas três amostras de cada mistura de argamassa.

Foram adotadas dimensões de 30x30x3cm para as formas de compensado, totalizando um volume de $2.700 \mathrm{~cm}^{3}$, cada forma. As mesmas foram parafusadas para que após a cura fossem desmoldadas com maior facilidade, sem comprometer as placas de argamassa. Foram realizados os cálculos para o quantitativo de materiais a ser utilizado nas amostras.

Os estudos foram elaborados com três mistura de argamassas distintas: a primeira sem nenhum aditivo, a segunda com aditivo 1 e a terceira amostra com aditivo 2. Cada mistura foi feita separadamente, para que não houvesse intervenção de aditivos em misturas subsequentes. Após cada mistura foram limpos os instrumentos de pesagem e de mistura dos elementos.

Após pesados, os materiais foram adicionados a um misturador mecânico de baixa rotação, para que houvesse uma mistura homogênea da argamassa. Os aditivos foram diluídos na água antes de serem acrescidos à mistura, conforme indicação de ambos os fabricantes, e adicionados à mistura conforme a Figura 2. Com o auxílio de colher de pedreiro, foram retirados os materiais que ficaram retidos nas paredes e nas pás do misturador. 
Parte do material foi reservada para elaboração do teste de consistência, a fim de analisar se a mistura da amostra está de acordo com o solicitado para este tipo de argamassa, conforme a NBR 13276 (ABNT, 2002). O ensaio foi realizado sobre uma mesa de consistência onde é colocado um molde tronco-cônico preenchido com $1 / 3$ da altura do tronco com argamassa e assentado em 15 golpes, após foi preenchido com mais 1/3 da altura do tronco com argamassa e assentado em 10 golpes e por fim, preenchido o restante do molde e assentado com 5 golpes. O material que fica retido acima do molde foi retirado com o auxílio de uma colher de pedreiro, após foi feito o alisamento da superfície superior. O molde foi retirado cuidadosamente para que não alterasse as características da amostra. A mesa de consistência possui um sistema que aplica golpes, espalhando a massa sobre a mesa, a qual foi aplicado 1 golpe a cada segundo durante 30 segundos, conforme a Figura 3. Logo após o último golpe, foram medidas duas distâncias perpendiculares, com o auxílio de um paquímetro, e calculadas as médias das medidas retiradas, conforme demonstrado na Figura 4 . O valor adequado para espalhamento da massa de argamassas é de $260 \mathrm{~mm}$ conforme trabalhabilidade do material.

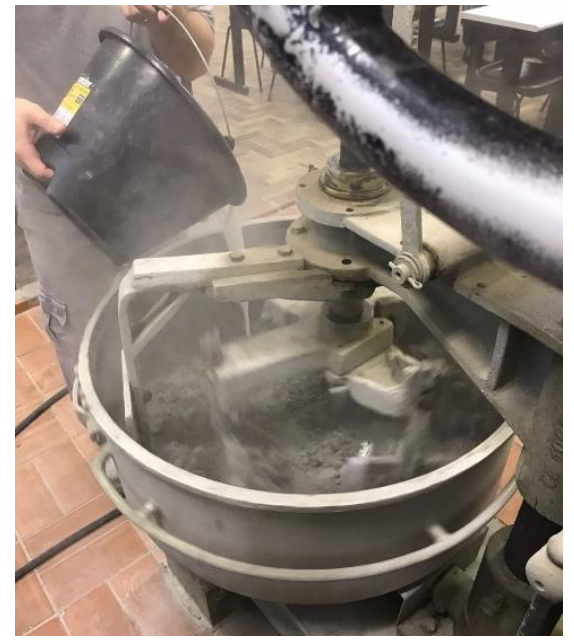

Figura 2: Mistura de materiais.

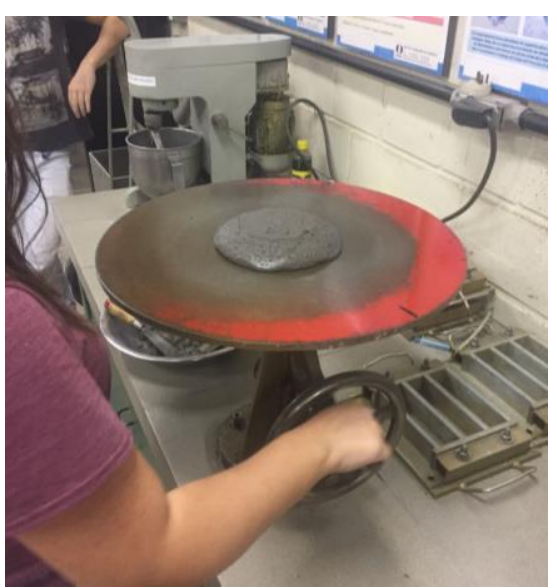

Figura 3: Aplicação de golpes na mesa de consistência.

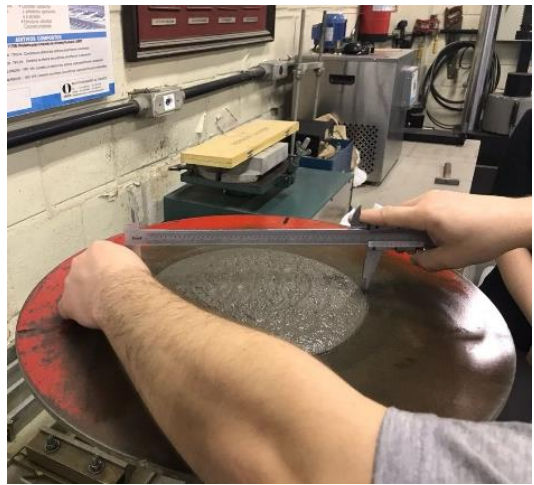

Figura 4: Medição de diâmetro da amostra.

Confirmadas das características do material, a argamassa foi distribuída nas formas de compensado. Foi disposta em duas camadas de $15 \mathrm{~mm}$ de espessura de argamassa nas formas: a primeira foi colocada na forma com o auxílio de uma pá e posteriormente reguado. Em seguida, foi colocada a segunda camada com $15 \mathrm{~mm}$ e desempeno da superfície final (NBR 9574, 2008). As placas foram deixadas em cura por 4 dias para a desforma das mesmas, para apuração dos resultados, foi aguardado 28 dias para a cura total da argamassa.

O ensaio estudado foi uma adaptação da NBR 14858 (ABNT, 1997), referente a permeabilidade em telhas de concreto, que é realizado com um tubo transparente de $35 \mathrm{~mm}$ de diâmetro interno e com $250 \mathrm{~mm}$ de coluna d'agua. Na Norma, é representada com a Figura 5 para o ensaio de verificação de permeabilidade.

Neste trabalho, foi utilizado um tubo de PVC branco com diâmetro interno de $40 \mathrm{~mm}$ e $300 \mathrm{~mm}$ de altura, para colocação de $250 \mathrm{~mm}$ de altura de coluna d'agua. Foram realizadas marcações diagonais nas amostras para que fosse estabelecido o centro das mesmas. Os tubos de PVC receberam marcações com caneta em seu exterior, marcando a medida de 250 $\mathrm{mm}$ de altura. Ele foi apoiado no centro das amostras e foi colado com silicone em todo o seu perímetro. A aplicação do silicone foi realizada com muito cuidado, para que não ficassem regiões sem a devida aderência entre amostra e tubo. Os vazios foram preenchidos manualmente, firmando o silicone ao tubo e à amostra de argamassa conforme a Figura 6 . Após a secagem do silicone, foi adicionado água no interior do tubo e deixado em local ventilado e protegido de intempéries, por 24 horas.

Para obtenção de mais informações e parâmetros para comparação entre amostras, foram feitas, além da leitura visual de cada amostra, a medição da altura de água inicial $(250 \mathrm{~mm})$ e final, a fim de comparar quanta água foi absorvida em cada amostra. Foram realizadas também as pesagens das amostras, para que houvesse um comparativo de peso das amostras antes da aplicação da coluna d'agua e após o ensaio e o tubo esvaziado. Esta medição será capaz de mostrar o quanto de água foi absorvido pelas placas de argamassa. 


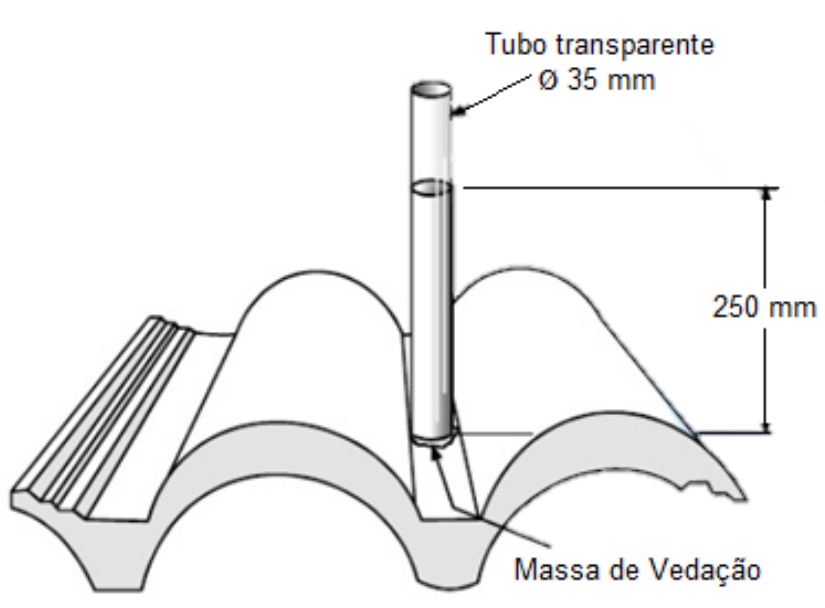

Figura 5: Verificação de permeabilidade.

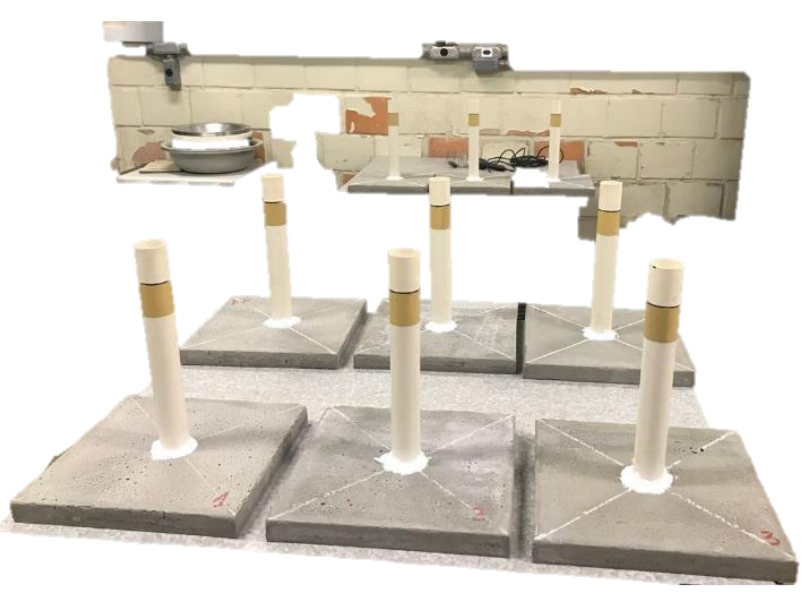

Figura 6: Fixação de tubo as amostras de argamassa.

\section{RESULTADOS}

A partir dos ensaios, foram realizadas análises visuais, medidas de altura de coluna d'agua (inicial e final) e pesagem de amostras (inicial e final). Foi adotado o número de três amostras para cada tipo de mistura para maior confiabilidade de resultados. As amostras 1 sem adição de aditivos, amostras 2 com aditivo 1 e amostras 3 com aditivo 2. Com a obtenção desses dados, foi possível comparar os resultados, verificando a diferença de materiais utilizados em cada mistura de argamassa.

\subsection{Comparação de massas}

As amostras foram pesadas antes da adição de água no tubo fixado nas amostras de argamassa e após as 24 horas de ensaio, em uma balança com precisão em gramas. Inicialmente foi introduzida uma pequena quantidade de água dentro do tubo e retirado o excesso. Visto que para a pesagem das amostras após a realização do estudo sempre ficará retida parte de água na região interna do tubo PVC. Foram obtidos os resultados apresentados na tabela 1.

Tabela 1 - Diferenças de peso das amostras iniciais e finais.

\begin{tabular}{|c|c|c|c|c|c|}
\hline Amostra & Peso inicial $(\mathrm{g})$ & Peso final $(\mathrm{g})$ & Diferença $(\mathrm{g})$ & Média (g) & Desvio padrão $(\mathrm{g})$ \\
\hline $1 \mathrm{~A}$ & 5520 & 5576 & 56 & \multirow{3}{*}{43,0} & \multirow{3}{*}{15,0} \\
\hline $1 \mathrm{~B}$ & 5359 & 5410 & 51 & & \\
\hline $1 \mathrm{C}$ & 5420 & 5442 & 22 & & \\
\hline $2 \mathrm{~A}$ & 5457 & 5477 & 20 & \multirow{3}{*}{17,3} & \multirow{3}{*}{2,5} \\
\hline $2 \mathrm{~B}$ & 5402 & 5417 & 15 & & \\
\hline $2 \mathrm{C}$ & 5255 & 5272 & 17 & & \\
\hline $3 \mathrm{~A}$ & 5085 & 5105 & 20 & \multirow{3}{*}{17,7} & \multirow{3}{*}{5,9} \\
\hline $3 \mathrm{~B}$ & 5175 & 5197 & 22 & & \\
\hline $3 \mathrm{C}$ & 5240 & 5251 & 11 & & \\
\hline
\end{tabular}

Conforme analisados os resultados da Tabela 1, foi possível constatar que a presença de aditivos em argamassas tem uma boa melhora na impermeabilidade das amostras. Nos resultados obtidos na pesagem da Amostra 1, nota-se que em média a absorção de água foi aproximadamente $150 \%$ maior que nas amostras com adição de impermeabilizantes à mistura. Ainda, foi possível concluir que os resultados obtidos para ambos os aditivos foram bem próximos, havendo um peso médio adicional à amostra de $17,5 \mathrm{~g}$.

\subsection{Comparação de altura de coluna d'agua}

Como o estudo de base, se baseou na NBR 14858 (ABNT, 1997), fez-se necessária a comparação de altura de coluna d'agua das amostras. A fim de que fosse medido o quanto de água passou ou ficou retida dentro das amostras. Como o estudo realizado foi uma adaptação, foi utilizado um tubo de PVC branco, que para facilitar a medição foi marcada a altura exatamente ao tubo na medida de $250 \mathrm{~mm}$. Com o auxílio de uma lâmpada, a tubulação foi iluminada para que pudesse ser visualizada a linha de marcação com maior facilidade pelo lado externo do tubo. As amostras foram preenchidas com água com o auxílio de uma bisnaga pequena para que houvesse uma precisão e cuidado maior do 
preenchimento até a medida indicada. Após 24 horas (conforme determinado na Norma), em local fechado e protegido de intempéries, foi medida a altura de água final presente na tubulação. Com uma régua, foi medida a altura final de água na tubulação. Os resultados obtidos estão representados na Tabela 2.

Tabela 2 - Diferença de alturas da coluna de água iniciais e finais.

\begin{tabular}{|c|c|c|c|c|}
\hline Amostra & Peso inicial $(\mathrm{g})$ & Peso final $(\mathrm{g})$ & Diferença $(\mathrm{g})$ & Média (g) \\
\hline $1 \mathrm{~A}$ & 250 & 196 & -54 & \multirow{3}{*}{$-44,3$} \\
\hline $1 \mathrm{~B}$ & 250 & 196 & -54 & \\
\hline $1 \mathrm{C}$ & 250 & 225 & -25 & \\
\hline $2 \mathrm{~A}$ & 250 & 230 & -20 & \multirow{3}{*}{$-17,7$} \\
\hline 2B & 250 & 235 & -15 & \\
\hline $2 \mathrm{C}$ & 250 & 232 & -18 & \\
\hline $3 \mathrm{~A}$ & 250 & 220 & -30 & \multirow{3}{*}{$-22,7$} \\
\hline $3 \mathrm{~B}$ & 250 & 227 & -23 & \\
\hline $3 \mathrm{C}$ & 250 & 235 & -15 & \\
\hline
\end{tabular}

Conforme analisados os resultados da Tabela 2, foi possível constatar que a presença de aditivos em argamassas tem uma boa melhora na permeabilidade das amostras. Na Amostra 1, houve em média uma redução de coluna d'agua de 44,3 cm. Já nas amostras com presença de aditivos, houve uma diminuição de 150 a 90\% menos que na Amostra 1.

\subsection{Análise visual}

Os todos os casos foram realizados análises visuais na região superior e inferior das amostras. Em nenhuma das amostras houve gotículas de água na região inferior, somente umidade em formato circular. Após a medição da altura de água final, a água foi derramada de dentro do tubo e analisada a parte inferior da amostra. Foram registradas fotos de todas as situações para que houvesse uma análise posterior das mesmas. As fotos foram separadas em conjunto com as fotos de cada tipo de amostra, conforme pode ser observado na figura 7.

A partir da análise visual da região inferior, foi possível ter uma interpretação sobre a permeabilidade de água das amostras. Nas amostras 1 foi possível notar que houve uma maior absorção de água, visto que o diâmetro de umidade da parte inferior das amostras foi maior que nas amostras seguintes.

Nas Amostras 2 com presença de aditivos, foi notória a diferença de permeabilidade das amostras. Os diâmetros, quando comparados com as Amostras 1, têm seu diâmetro muito reduzido. Inclusive na Amostra 2C, não houve passagem de umidade representativa para a região inferior da placa, não houve umidade visível como nas demais amostras.

O mesmo pôde ser observado nas Amostras 3, quando comparado as Amostras 1, tem seu diâmetro muito reduzido. Ao contrário do que foi visualizado na Amostra 2C, nas amostras não houveram casos de placas sem umidade na região inferior.

Em geral, as amostras com aditivo tiveram a região inferior com umidades semelhantes umas às outras, diferentemente da encontrada nas Amostras 1, sem a adição de aditivos. Na região superior das amostras, houve uma semelhança de umidade em todos os corpos de prova, como pode ser visto na Figura 8.

Na Figura 8, pode ser realizada a avaliação de todas as amostras lado a lado. As amostras foram ordenadas horizontalmente e com identificação em cada uma delas para melhor visualização. Segue a ordem inferior para a superior, sendo as Amostras 1 inferiores à Amostras 2 intermediárias e Amostras 3 as superiores. 

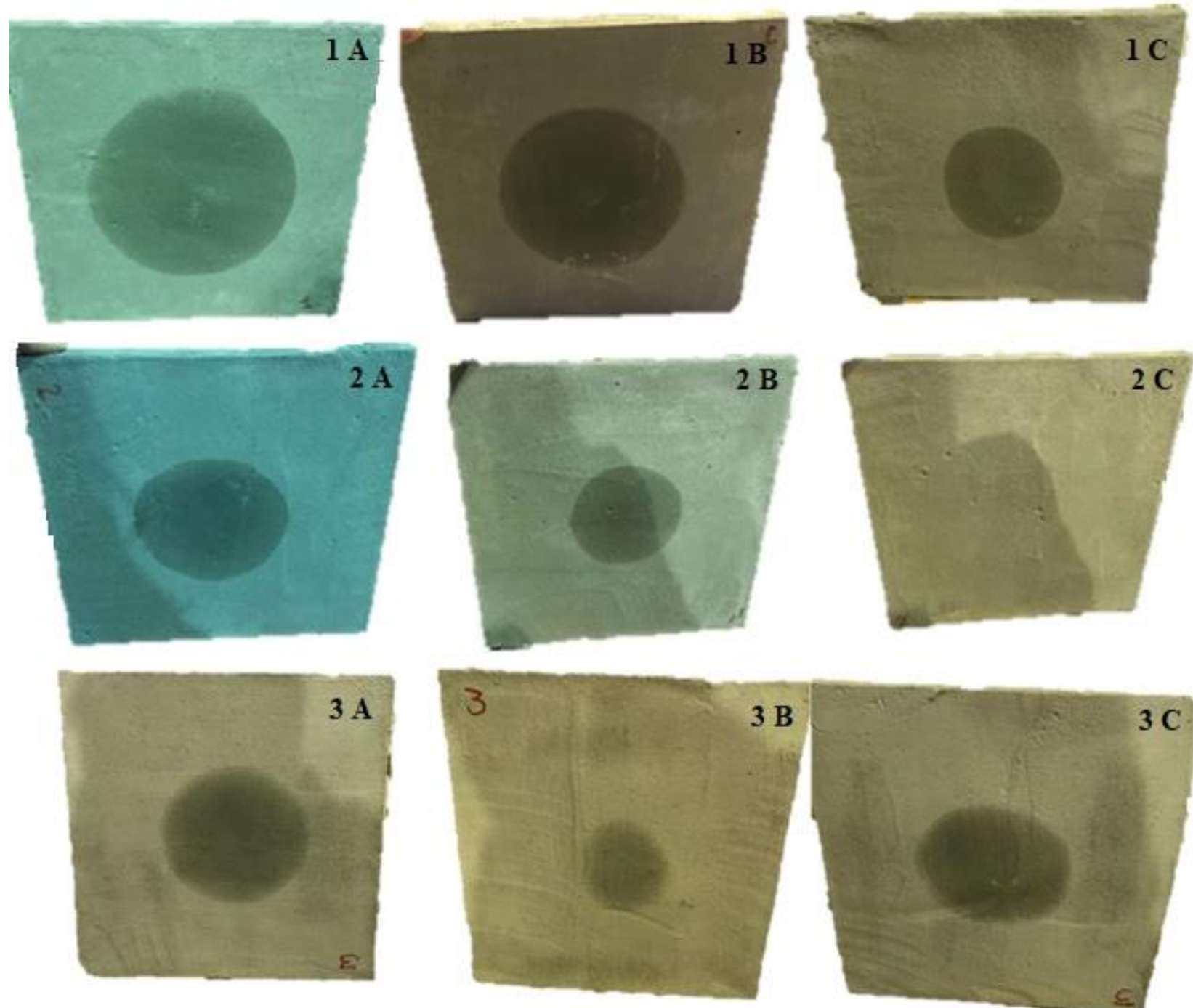

Figura 7: Análise visual da mancha d'água nas faces inferiores das diferentes amostras.

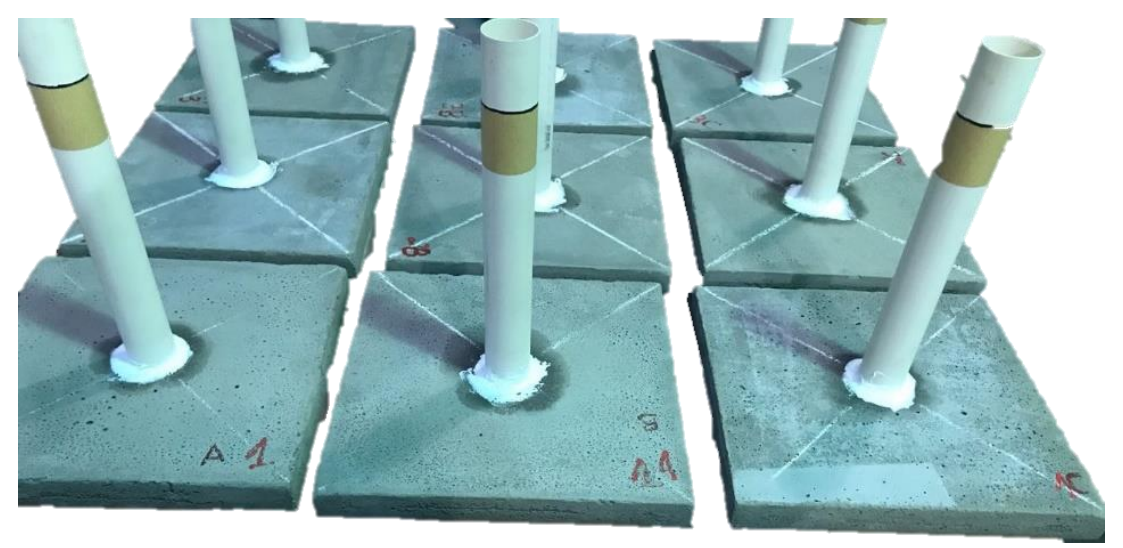

Figura 8: Análise visual da mancha d'água nas faces superior das diferentes amostras.

\section{CONSIDERAÇÕES FINAIS}

Foram realizados neste trabalho, estudos para comparação de desempenho de aditivos hidrofugantes quando acrescidos à mistura de argamassas comumente utilizadas em vigas de baldrame. 
Para a realização deste estudo, foram executadas amostras de argamassas com espessura de 30 mm realizadas em três misturas distintas, uma sem adição de impermeabilizante aditivo hidrófugos outras duas com. Aplicou-se coluna d'agua sobre as amostras a fim de medir o quanto as amostras se tornaram menos permeáveis.

Foram analisadas diferença de nível de altura d'agua das amostras inicialmente $(250 \mathrm{~mm})$ e a altura ao final das 24 horas. Além disso, foram pesadas as amostras antes da colocação de água e após o período de ensaio e com a água retirada da sua tubulação. Para uma análise completa, houve uma avaliação da região inferior e superior de todas as amostras.

Para todos as avaliações realizadas corroboram que a presença dos de aditivos hidrofugante contribui para menor permeabilidade da argamassa. Tanto a variação da massa das amostras quanto a variação da altura da coluna de água foram menores para as amostras com aditivo, comparrativamente a amostra referência. Também pode-se avaliar qualitativamente que a mancha de água na face inferior das amostras com aditivo hidrofugante foi menor do que a mancha nas amostras sem referido aditivo. Contudo há que se resaltar que em nenhuma das amostras foi verificada a formação de gotas d'água.

Para os próximos trabalhos sugeri-se a aplicação de esforços as amostras, visto que a mesma sofrerá pressão e esforços da estrutura quando submetida a impermeabilização. Além disto, pode ser realizada uma verificação de características das placas como fissuração pois faz papel importante na permeabilidade da edificação. Outra sugestão seria o estudo em demais produtos para maior conhecimento sobre a eficácia de mais produtos.

\section{AGRADECIMENTOS}

Os autores agradecem a disponibilização dos laboratórios de materiais de construção civil da PUCRS para realização dos experimentos deste trabalho.

\section{REFERÊNCIAS}

ADIFIX. Otimum conceito em impermeabilizantes. Disponível em: <http://www.otimum.com.br>. Acesso em: 20 março. 2018.

ASSOCIAÇÃO BRASILEIRA DE NORMAS TÉCNICAS. NBR 9574: Execução de impermeabilização. Rio de Janeiro, 2008.

ASSOCIAÇÃO BRASILEIRA DE NORMAS TÉCNICAS. NBR 9575: Impermeabilização - Seleção de projetos. Rio de Janeiro, 2010.

ASSOCIAÇÃO BRASILEIRA DE NORMAS TÉCNICAS. NBR 13281: Argamassa para revestimento de paredes e tetos - Requisitos. Rio de Janeiro, 2005.

ASSOCIAÇÃO BRASILEIRA DE NORMAS TÉCNICAS. NBR 15575: Edificações habitacionais - Desempenho. Rio de Janeiro, 2013.

BARBOSA, R. M. E. Patologia da impermeabilização de edificações: Aspectos técnicos e metodológicos. 2018. Trabalho de conclusão de curso (graduação Engenharia Civil) - Universidade Federal do Rio de Janeiro. Rio de Janeiro, 2018.

BIFF, G. Spillere. Análise de diferentes tipos de argamassa de revestimento. 2013. Trabalho de conclusão de curso (graduação em Engenharia Civil) - Universidade do Extremo Sul Catarinense, Criciúma, 2013.

CRUZ, Julio Henrique Pinto, A Manifestação Patológica de impermeabilização com uso de sistema não aderido de mantas asfálticas: avaliação e análise com auxílio de sistema multimidea. Porto Alegre: UFRGS, 2003. Dissertação de Mestrado - Universidade Federal do Rio Grande do Sul, Porto Alegre, 2003.

CUNHA, A.G.; NEUMANN, W. Manual impermeabilização e isolamento térmico. Rio de Janeiro: Texsa Brasileira, 1979. 
FERREIRA, Romário. Conhecendo os impermeabilizantes. 2012. Disponível em: <http://www.equipedeobra.pini.com.br/construcao-reforma/44/conhecendo-osimpermeabilizantes-veja-quais-sao-ossistemas-de-245388-1.aspx. . Acesso em: 15 abril. 2018.

ITAMBÉ - Disponível em: <http://www.cimentoitambe.com.br/wp-content/themes/itambe-cimentocerto/_assets/pdf/relatorios/2013-13/CP-IV-32-RS.pdf. . Acesso em: 20 março. 2018.

INTERCEMENT-CIMPOR-Disponível em: <http://www.brasil.intercement.com/ProdutosServicos/detalhes_cimento/10> Acesso em: 20 março. 2018.

INSTITUTO BRASILEIRA DE IMPERMEABILIZAÇÃO. Disponível em: <http://ibibrasil.org.br/2017/10/17/o-que-eimpermeabilizacao/ . Acesso em: 20 março. 2018.

LIMA, J. L. de A.; PASSOS, F. U.; COSTA, D. B. Processo integrado de projeto, aquisição e execução de sistemas de impermeabilização em edifícios residenciais. Ambiente Construído, Porto Alegre, v. 13, n. 3, p. 59-77, jul./set. 2013.

NAZARIO, D. Manifestações das patologias construtivas nas edificações públicas da rede municipal de Criciúma: Inspeção dos sete postos de saúde. 2011. Trabalho de conclusão de curso (graduação em Engenharia Civil) Universidade do Extremo Sul Catarinense, Criciúma, 2011.

OLIVEIRA. I. S. A importância da impermeabilização da viga de baldrame e as patologias decorrentes da falta ou da má execução. 2014. Trabalho de conclusão de curso (Graduação em Engenharia Civil) - Universidade Católica de Brasília, Distrito Federal, 2014.

PINTO, J.A.N. Patologias de impermeabilização. Santa Maria: Multipress, 1996.

Ripper, E. Como evitar erros na construção. 1996. Editora PINI, São Paulo.

SOUZA, M. F. Patologias ocasionadas pela umidade nas edificações. 2008. Monografia (Especialização em Construção Civil) - Universidade Federal de Minas Gerais, Belo Horizonte, 2008.

VEDACIT - Manual técnico de impermeabilização de estruturas. $4^{\circ}$ Edição. Disponível em: www.vedacit.com.br (Acessado em 15/04/2018).

WEIDMANN, D. F.; CASALI, J. M.; JUNIOR, L. R. P. Avaliação do desempenho de aditivos hidrofulgantes e impermeabilizantes empregados em blocos de concreto para alvenaria estrutural. 2006. Artigo (XI Encontro Nacional de Tecnologia no Ambiente Construído) - Florianópolis, Santa Catarina, 2006. 